\title{
Mathematical modelling of nitrogen flow in growing pigs and lactating sows
}

\author{
BY JAMES E. PETTIGREW
}

Department of Animal Science, University of Minnesota, St Paul, MN 55108, USA

Mathematical modelling as applied to growing pigs and lactating sows is a structured method for deriving quantitative estimates of the productive performance of the animal under varying diets and other conditions. A simple overview is that a model starts with a clear quantitative description of the animal (usually including body protein and fat content), estimates daily protein and fat accretion, updates the description, and repeats those estimates and updates until the desired end-point is reached. This is conceptually simple, but in practice it is quite challenging.

A recent book edited by Moughan et al. (1995) provides a thorough description of modelling as applied to the pig. Progress in modelling the pig continues, as shown by recent publication of a model of digestion in the pig (Bastianelli et al. 1996).

Models that predict whole-animal performance can vary in the level of aggregation at which they operate. Some models work at the metabolic level, predicting the flows of $\mathrm{C}$ and $\mathrm{N}$ through metabolic pathways. They do not work at the level of individual reactions, but aggregate those individual reactions into pathways. Others work at the level of lean and adipose tissues, predicting the rates of accretion of protein and fat in these tissues. They thus aggregate all the metabolic transactions into simple expressions of protein and fat accretion, so they are more highly aggregated than are the metabolic models. Still others operate at the whole-animal level, and are the most highly aggregated of all. They often are built of regression equations relating body-weight gain to variables such as dietary lysine concentration or stocking density, and thus aggregate accretion of protein, fat, water, ash, and gut contents into whole-body growth. They are considered empirical models because they are based entirely on observations, with no considerations of the underlying mechanisms. Nutrient-partitioning and metabolic models are considered mechanistic, because they are structured to reflect our perceptions of the mechanisms of animal growth. They admittedly contain empirical elements, because in some areas (e.g. relationship between backfat thickness and body fat content) we have no useful concepts of the underlying mechanisms. The terms empirical and mechanistic as applied to models are relative, not absolute, so there are degrees of mechanism. Metabolic models are more mechanistic than are nutrient-partitioning models, because there is a greater separation between the level of the outputs (whole-animal) and the level at which they are built than in the case of nutrient-partitioning models.

Empirical models can be very accurate within the range of conditions in which they were developed, but are unreliable when used in other conditions. Mechanistic models are more reliable over a wider range of conditions because they are built on biological mechanisms. Therefore, they are usually more useful. However, as models become more mechanistic, reliable quantitative estimates of model variables are often more difficult to obtain, and that reduces accuracy of model predictions.

In mathematical modelling, as in any other type of research, it is important to define one's objectives clearly. Often, an objective is to provide a management tool for use in commercial pork production. The desired model could be used to address 'What if ...' questions. For example, the model could predict the effects of reducing the dietary lysine concentration, or of improved control of ambient temperature in the pig building. For these 
purposes, nutrient-partitioning level models are likely to be most useful because of inadequate information for parametrizing metabolic models. Another common objective is to aid in understanding biological mechanisms. For this purpose, metabolic models will often be most useful.

In modelling at any level of aggregation, it is critical to evaluate the performance of the model. There are three components of model evaluation (Black, 1995). First, the general behaviour of the model is evaluated by varying inputs and subjectively assessing whether the nature of the response in model predictions is similar to that predicted by an expert in the field. Second, key model variables are varied to identify those to which model predictions are especially sensitive. Finally, the model should be used to simulate experimental treatments reported in the scientific literature, and model predictions compared with measured values.

In the present paper, nutrient-partitioning models will be described in the context of growing pigs, and metabolic models in the context of lactating sows. Then a brief list of the most critical information needs for further progress in modelling will be proposed.

\section{GROWING PIGS: DESCRIPTION OF MODELLING AT THE NUTRIENT-PARTITIONING LEVEL}

Most mathematical models applied to pigs are models of growing pigs at the nutrientpartitioning level. Dietary energy and amino acids are apportioned to maintenance functions, protein accretion, and fat accretion. Estimates of maintenance requirements are obtained from the literature, and present information appears satisfactory for this purpose. The bigger challenge is prediction of the amount of protein accreted, which in turn determines the partitioning of dietary energy between accretion of protein and fat.

\section{Protein accretion rate}

Protein accretion can be limited by any of three factors: (1) animal potential, (2) energy intake, (3) amino acid intake. Models usually identify the most limiting of these factors, and estimate the amount of protein accretion allowed by that limit.

Animal potential. There is enormous genetic variation among pigs in the potential protein accretion rate (the protein accretion rate at optimal nutrient intake), and models often incorporate estimates of potential protein accretion rate at any body weight for individual genetic strains. However, there are many other factors besides genetics that appear to have important effects on the potential protein accretion rate. Among these factors are sex, health, ambient temperature, and housing conditions including stocking density. Therefore, it is inadequate to consider only strain in estimating the potential protein accretion rate. The quantitative effects of most of these factors on protein accretion rate are inadequately described. Health is an especially difficult factor to incorporate into models. It has recently become clear that degree of health has major effects on protein metabolism (Klasing, 1994) and performance (Walker \& Wiseman, 1994; Williams et al. 1994) of pigs. However, it is difficult to describe the degree of health quantitatively, and its quantitative effects on protein accretion rate are not well defined. In any consideration of potential protein accretion rate it is necessary to define clearly whether the measurement is of protein accretion in the entire empty body or in only the carcass.

A simulation model of the growing pig requires a mathematical description of protein accretion $v$. live weight (a protein-accretion curve) for the pigs and conditions simulated. It is unlikely that the same shape of curve is appropriate for all pigs. Recently attention has been given to estimation of such curves, but there is not good agreement on their shape 
(Moughan, 1995; Schinckel et al. 1996). Widespread application of models to commercial pig production will require development of methods for estimation of these curves for individual production situations (de Lange \& Schreurs, 1995).

Energy intake. The quantitative relationship of protein accretion rate to energy intake, when the diet is adequate in amino acids and other nutrients, has a linear-plateau form similar to that shown in Fig. 1 (Standing Committee on Agriculture, Pig Subcommittee, 1987). In some experiments with young pigs (less than about $50 \mathrm{~kg}$ body weight; Standing Committee on Agriculture, Pig Subcommittee, 1987) or in very lean pigs (Standing Committee on Agriculture, Pig Subcommittee, 1987; Bikker et al. 1996) there is no plateau, and the response appears linear. It may be that the linear slope is, in reality, not exactly linear, that the plateau is not exactly flat, or that the transition from one to the other is not sharp but gradual. However, the form of response shown (Fig. 1) appears to fit the available data remarkably well. It is, therefore, a good approximation of the true response form, accurate enough for most purposes. The complex and interacting metabolic control systems that produce this response (and other responses) are under no compulsion to produce results that are convenient for us to describe mathematically! Such response forms, therefore, should be considered empirical, not mechanistic.

The slope of the ascending line in Fig. 1 is a measure of the animal's leanness, because it reflects the proportion of the animal's energy intake above maintenance that is partitioned to protein accretion $v$. fat accretion. Both the slope of this line and the level of the plateau vary among animals and environments. It is likely that many animals with a high plateau value also have a steep slope (Standing Committee on Agriculture, Pig Subcommittee, 1987), and this association is incorporated into some models (Black et al. 1986). However, I suggest caution because this association may be far from perfect.

The slope of the ascending line gradually flattens as the pig ages (Fig. 2; Black et al. 1986). The level of the plateau rises and then falls as the pig ages, reflecting the protein accretion curve described previously.

Once the quantitative relationship between energy intake and protein accretion rate is established, it is a straightforward process to determine the protein accretion rate that can be supported by a given rate of energy intake. In this relationship, energy can be expressed as digestible, metabolic or net energy.

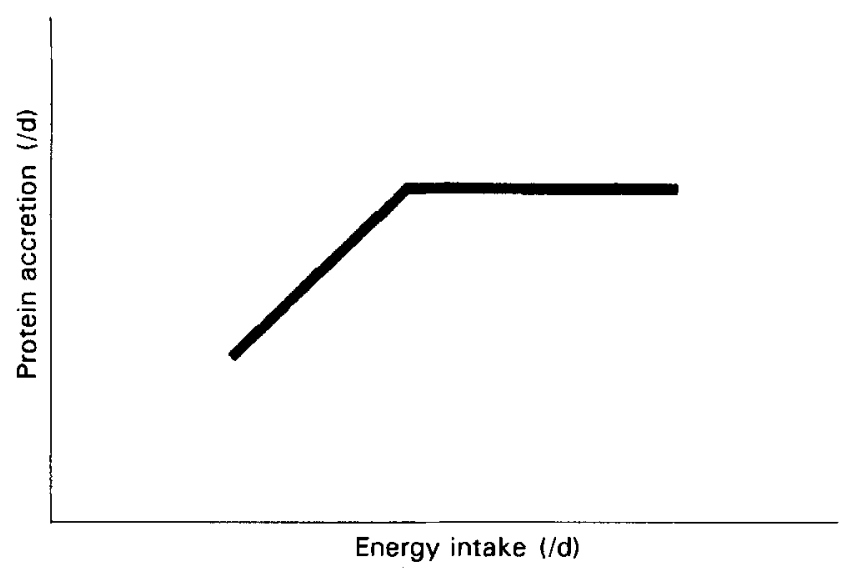

Fig. 1. The response of protein accretion rate to energy intake; a linear-plateau form of response. 


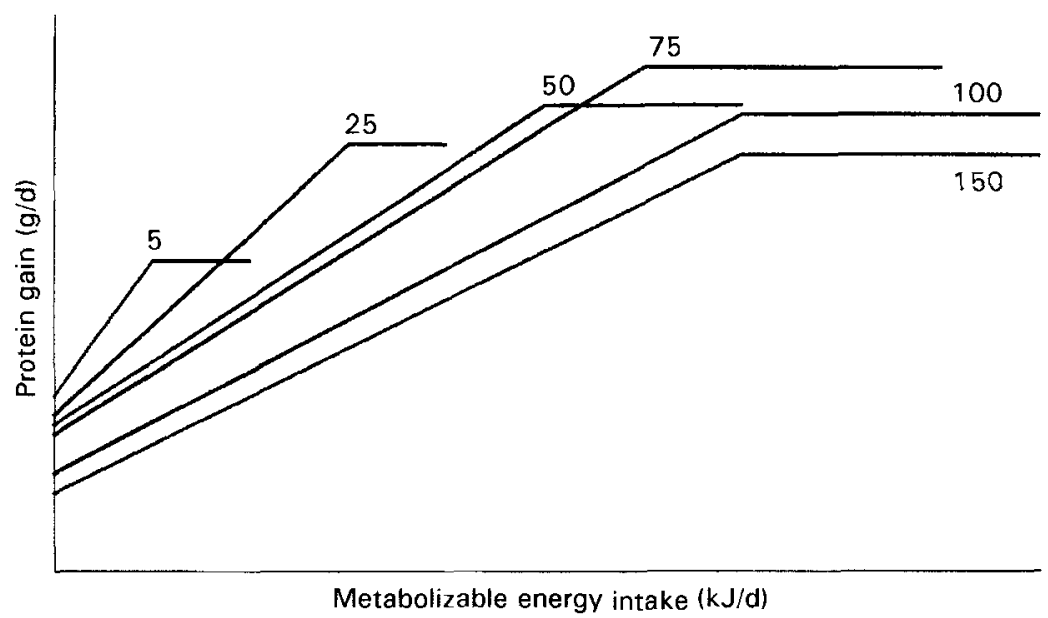

Fig. 2. Protein accretion rate $v$. energy intake at various body weights. Values shown refer to body weight $(\mathrm{kg})$.

Amino acid intake. It is useful to focus on intake of the limiting amino acid, which is lysine in most practical diets. Amino acid intake can be expressed as the total amount in the diet, or as the amount of digestible (apparent, true, or standard) amino acid consumed.

The response of protein accretion rate to lysine intake is often assumed to be of the linear-plateau form (Fig. 3). This assumption may be less valid in the case of amino acid intake than in the case of energy intake, and the actual response may be some non-linear form, an example of which is indicated in Fig. 3. The shape of response has proved remarkably difficult to define. It is often difficult to determine to what extent the shape of resnonse described in a report of an experiment is produced by the data, and to what extent it is determined by the mathematical equation form chosen by the investigators. Consider a quadratic equation form, as a simple example. If the data set includes observations at lysine intake levels above the requirement, the quadratic term in the model will be large. As a result the line will curve throughout the range of lysine intakes. The quadratic equation form is not capable of showing a linear response over part of the range of intakes and a curved response over another part. Most investigators report only one equation form, and it may be chosen rather arbitrarily. An exception is found in the work of Bikker (1994), who measured protein accretion at several levels of intake of a protein mixture with constant amino acid composition. He applied four different equation forms to the data. The best fit was obtained with a model described as 'linear-plateau with smooth transition'. However, another problem was illustrated by the results. The range of $R^{2}$ for the four models was only from 0.9174 down to 0.9089 . These fits are so similar that it is difficult to conclude with confidence that one model is better than the others, even though the differences in shape of response are large enough to be of practical importance. The degrees of fit of the four equations are statistically indistinguishable.

The slope of the ascending line (Fig. 3) is a measure of: (1) the marginal efficiency of lysine use for deposition, and (2) the lysine content of the accreted protein. If we assume for the moment that changing the amino acid intake has only small effects on the amino acid composition of accreted protein, the slope relates mostly to marginal efficiency of lysine use. The linear-plateau form is consistent with a constant marginal efficiency as lysine intake increases all the way to the requirement. A curved response form reflects a 


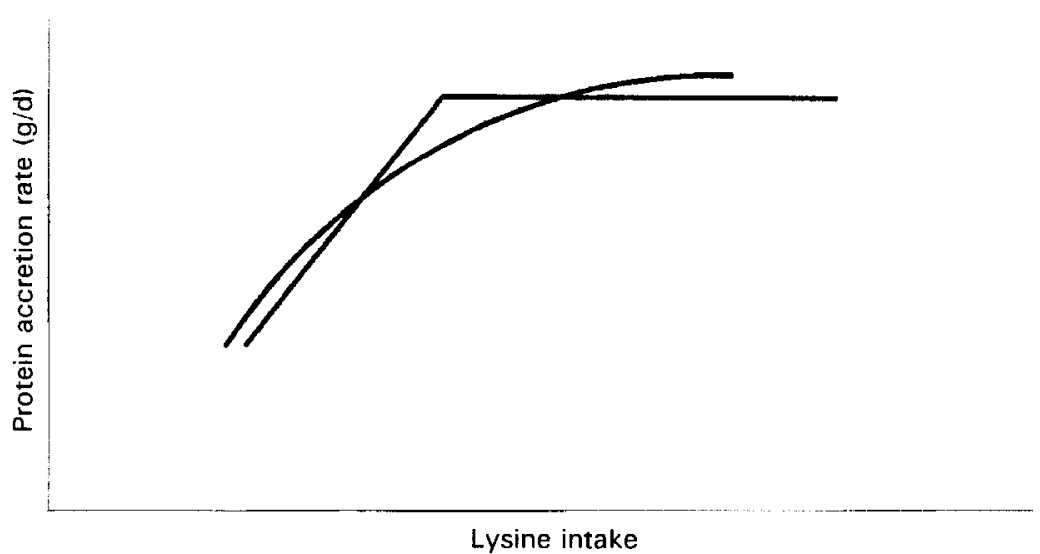

Fig. 3. Two alternative forms of response of protein accretion rate to lysine intake, when lysine is limiting. One line shows the linear-plateau form of response, the other a curved form of response.

declining marginal efficiency with increasing lysine intake. Estimates of marginal efficiency vary widely, but are substantially below 1.0 (Batterham et al. 1990; Krick et al. 1993; Bikker, 1994).

The assumption that the amino acid composition of the accreted protein is constant, made temporarily, previously, may not be valid. The proportion of protein deposited in the viscera, as opposed to the carcass, is greater at higher feed intake levels (Bikker, 1994). The amino acid composition of visceral protein differs from that of carcass protein, so the overall composition of accreted protein must vary to some extent.

It is useful to consider what happens to the lysine that is not deposited in body protein, but is in some way lost from the body. Some of this lost lysine, about $10 \%$ of that absorbed according to a recent estimate (Möhn et al. 1996), is oxidized. Presumably, it is not possible to stop the lysine oxidation pathway completely. The remainder is lost from the body, either in sloughed skin and hair, or in secretions and intestinal cells transferred to the intestinal lumen and not retrieved. There is a pressing need for more quantitative information about endogenous amino acid losses and factors that affect those losses.

Some pig growth models incorporate a linear-plateau relationship between protein accretion rate and lysine intake. It is much more difficult to incorporate a curved response form in simulations of pigs with varying potential protein accretion rate. Some more sophisticated models avoid assumptions about the shape of that response by using the limited information available to estimate endogenous amino acid losses in each situation simulated.

Other amino acids. Lysine is not always the limiting amino acid, and models can predict protein accretion rate when other amino acids are limiting. Two variables must be known for any amino acid considered. First is the maintenance requirement, and estimates are available (Fuller et al. 1989). Second is the relationship between protein accretion rate and intake of the limiting amino acid. If the linear-plateau form of response is assumed, the value for the slope for any amino acid: that of lysine is the inverse of the value for its requirement for growth: that of lysine. This is an ideal protein approach, but with requirements for growth separated from requirements for maintenance. If the model explicitly considers amino acid losses, then the amino acid composition of endogenous protein losses must be considered, along with the rate of oxidation, and the use of some amino acids for purposes other than direct incorporation into proteins. 
Nutrient requirement estimation. To estimate nutrient requirements using a model, simply simulate a range of levels of intake of the nutrient and identify the amount of the nutrient required to achieve the target level of predicted performance (often maximum protein accretion rate).

A different approach is being explored for use in estimating amino acid requirements for publication by the National Research Council in the forthcoming 10th edition of Nutrient Requirements of Swine (currently in preparation). This approach is not a simulation model, but uses the logic described previously in a structured method for factorial estimation of requirements under defined conditions.

\section{LACTATING SOWS: DESCRIPTION OF MODELLING AT THE METABOLIC LEVEL}

Lactating sows can be modelled at the nutrient-partitioning level (Black et al. 1986), but there may be a special advantage of modelling at the metabolic level in this case, as described later. A metabolic model of the lactating sow (Pettigrew et al. 1992a; modified by Pettigrew et al. 1993) is, to my knowledge, the only metabolic model reported for pigs. It draws heavily on the methods used earlier in modelling the dairy cow by Baldwin et al. (1987).

The model traces the flow of $\mathrm{C}$ and $\mathrm{N}$ from absorbed nutrients into pools of metabolites, through intermediary metabolism, into and out of body tissues, and into milk (Fig. 4). It moves through time. At each time-step it estimates the rate of flow along each arrow in Fig. 4 (and a few others not shown). Then it looks at each pool (box in Fig. 4), and constructs a differential equation describing the amount of material moving into and out of the pool. Finally, it integrates those differential equations. That produces new pool sizes and, thus, new substrate concentrations, for the next time-step.

The model predictions are determined by the estimates of the rate of flow along the arrows in Fig. 4. In general, four principles guide estimation of these rates:

(1) the kinetics (rates) apply to the entire transactions (metabolic pathways) shown in Fig. 4 , not to individual pathways within these pathways;

(2) the rate of a transaction is a function of the state of the animal. Specifically, the rates are usually determined by the concentrations of substrates, and sometimes by concentrations of inhibitors;

(3) most transactions are saturable with substrate, and the kinetics follow established patterns of saturable systems such as Michaelis-Menton kinetics. Mass action (firstorder) kinetics are also used in some metabolic models;

(4) most rates are expressed per unit tissue constituting the reaction site, to reflect differences in body size.

A limiting substrate is apportioned to competing reactions by assignment of Michaelis-Menton parameters, $K_{M}$ and $V_{\max }$. A transaction with higher priority for use of a substrate is assigned in models a lower value for $K_{m}$, reflecting a strategy that appears to be employed by the body.

An important difficulty in development of whole-animal metabolic models is the lack of reliable quantitative estimates of kinetic variables. The overall model cannot be more reliable than the quantitative data upon which it is built. Another important difficulty is encountered in attempting to incorporate the powerful role of metabolic hormones in predicting quantitative aspects of metabolism.

In spite of these difficulties, a metabolic model of the lactating sow (Pettigrew et al. $1992 a$ ) has produced predicted changes in body weight, body protein, and body fat in quite 


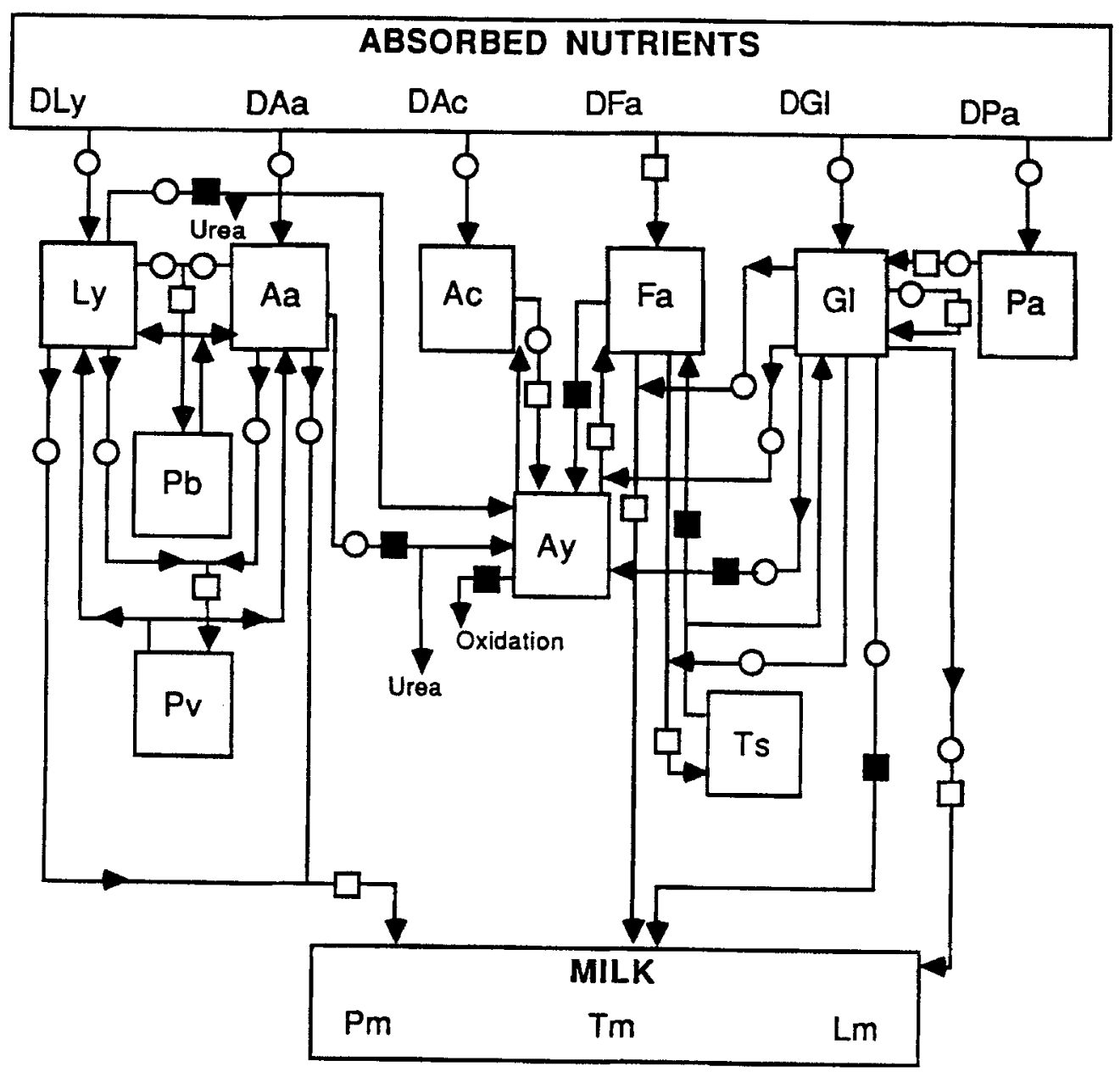

Fig. 4. Schematic representation of a model of lactating sow metabolism. State variables shown are: lysine (Ly), other amino acids (Aa), acetic acid ( $\mathrm{Ac}$ ), fatty acids ( $\mathrm{Fa})$, glucose (Gl), propionic acid ( $\mathrm{Pa}$ ), acetyl-Co $\mathrm{A}$ (Ay), protein in lean body $(\mathrm{Pb})$, protein in viscera $(\mathrm{Pv})$, storage triacylglycerol (Ts), and milk protein (Pm), fat (Tm), and lactose (Lm). DLy, DAa, DAc, DFa, DGI, DPa, driving variables, i.e. the quantity of the nutrient absorbed daily. Fluxes requiring and/or yielding adenosine triphosphate (ATP): (O), uses ATP in transport, ( $\square$ ), uses ATP in reaction; ( $\square$ ), produces ATP in reaction. (From Pettigrew et al. 1992a; reprinted with permission from Journal of Animal Science.) 
good agreement with measured values, at least in the situations simulated (Fig. 5; Pettigrew et al. 1992b).

\section{Reproductive performance}

A conceptual diagram of the connection of diet composition and intake during lactation to subsequent reproductive performance is shown in Fig. 6 (Pettigrew \& Tokach, 1993). This model suggests that the metabolic state of the lactating sow is a function of nutrient intake, modified by the rate of milk production and by the amount of body reserves. It is the metabolic state that is perceived to influence reproductive performance, either directly (e.g. direct effects on the ovary) or indirectly, through effects on reproductive hormone release and degradation. The model described previously (Pettigrew et al. 1992b) deals only with nutrient intake, metabolic state, milk production, and body reserves. It is not structured to address the connection between metabolic state and reproduction. The connections between reproductive hormones and reproduction are well defined, but the connections between metabolic state and either reproductive hormones or reproduction are not. Until these relationships are defined quantitatively, it will be difficult to predict reproductive performance by use of a model. Our research programme has recently focused on these relationships, and we are making some progress. It now appears that circulating concentrations of insulin (Booth, 1990; Pettigrew \& Tokach, 1993) and perhaps insulinlike growth factor-1 (Pettigrew \& Tokach, 1993) are components of the metabolic state that are particularly critical signals to the reproductive system. There is confusion about the timing of metabolic signals to the reproductive system (Foxcroft et al. 1995; Koketsu et al. 1996) which must be resolved before nutritional effects on reproduction can be satisfactorily modelled.

\section{INFORMATION NEEDS}

Further progress in modelling $\mathrm{N}$ flow in pigs will require information that is not now available. Four key areas of information needs are outlined.

\section{Potential protein accretion rate}

We need much more definitive quantitative information on potential protein accretion curves for pigs as affected by genetic strain, health, stocking density, ambient temperature, and other factors. That will require quantitative descriptions of strain and health status. We also need methods for defining protein accretion curves in individual situations in commercial pig production.

\section{Slope of protein accretion rate v. energy intake}

This measure of leanness is a critical variable in nutrient-partitioning models. We have some quantitative estimates of this variable (Black et al. 1986; Campbell \& Taverner, 1988; de Greef, 1992; Bikker, 1994) but these estimates do not appear to show a consistent pattern across experiments. We need further documentation of changes in this slope as the pig matures. We also need to know how genetic strain, health, stocking density, ambient temperature, and other factors affect this variable. 
(a)
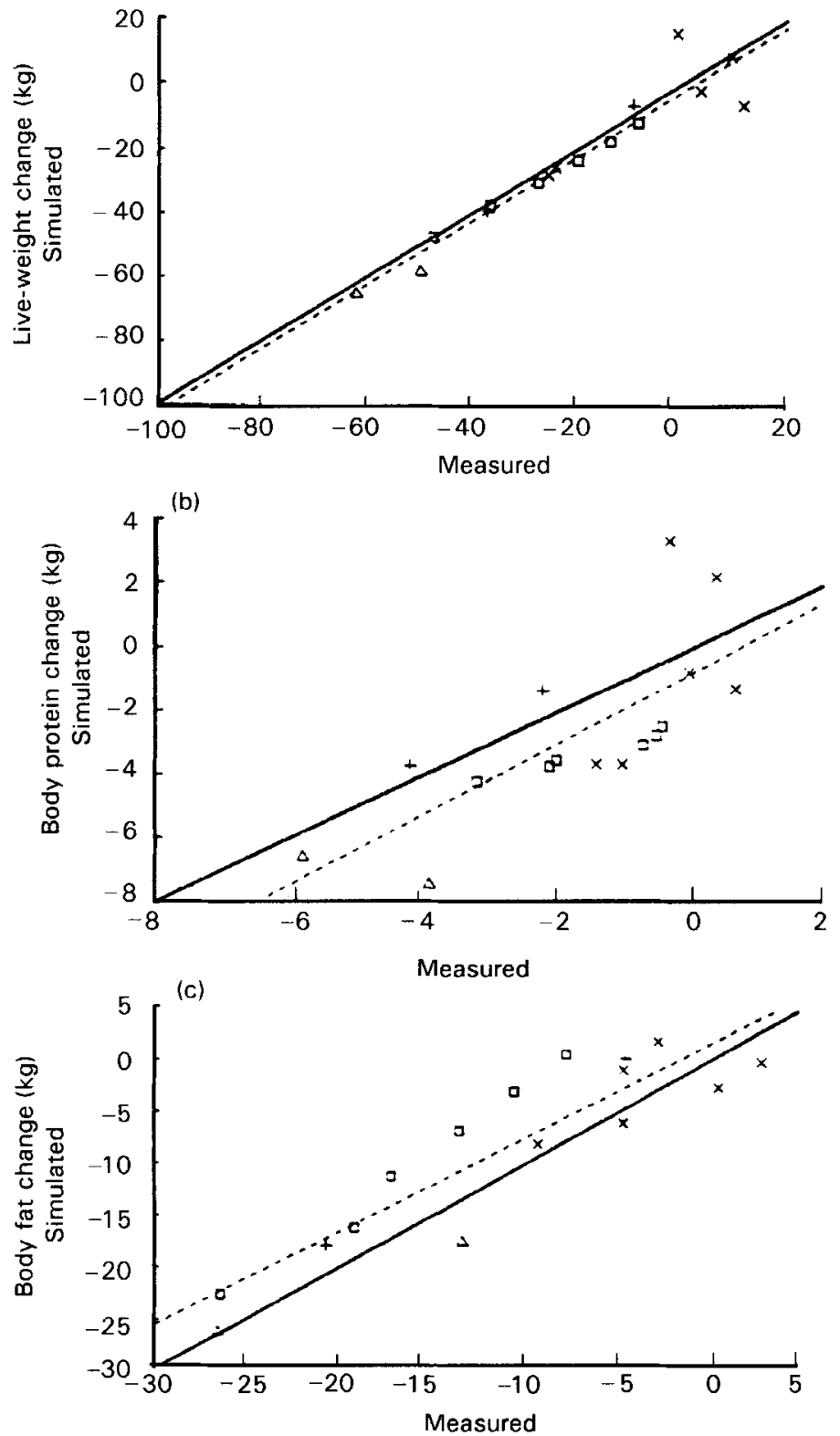

Fig. 5. Simulated $v$, measured values for change (gain or loss) of (a) live weight, (b) body protein content, and (c) body fat content during lactation in the pig. (- - ), Perfect agreement; (- - ), regression line. (a) $Y=-2.27$ (SE $2.52)+1.01 \quad(\mathrm{SE} 0.09) X, r^{2} 0.91 ;$ (b) $Y=-0.76$ (SE 0.66) $+1.12 \quad$ (SE 0.27)X, $r^{2} \quad 0.55 ; \quad$ (c) $Y=1.58$ (SE 1.58) +0.91 (SE 0.11)X, $r^{2}$ 0.82. (From Pettigrew et al. 1992b; reprinted with permission from Joumal of Animal Science.) 


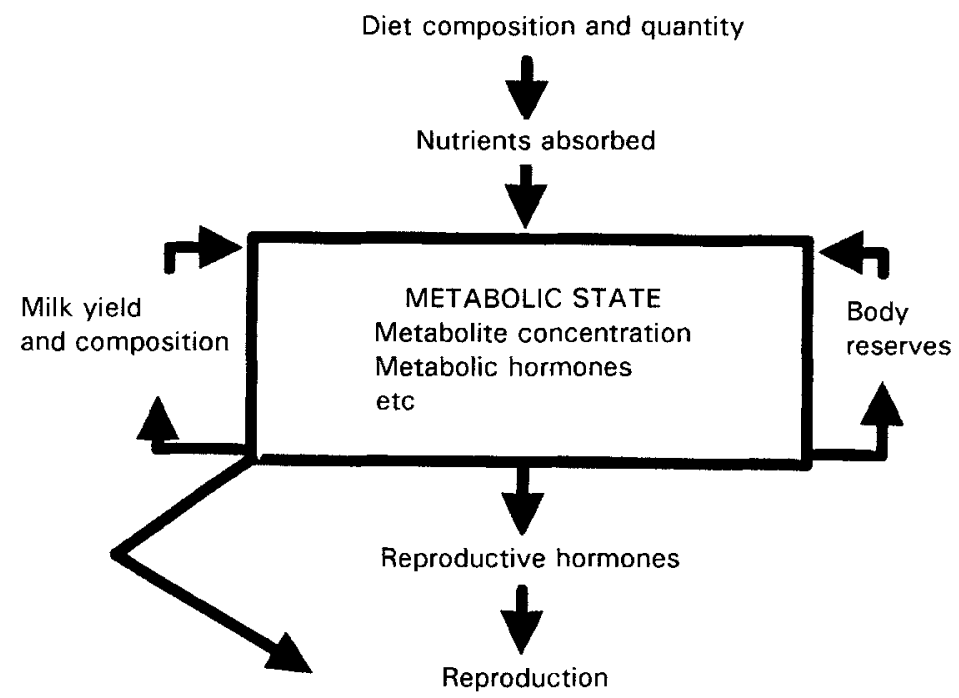

Fig. 6. Proposed cascade of biological responses connecting nutrition to reproduction in the sow. (From Pettigrew \& Tokach, 1993; reprinted with permission from Pig News \& Information.)

\section{Endogenous amino acid losses}

Our knowledge of the quantity of endogenous amino acids lost into the gut or oxidized in the tissues is very sketchy. We need more information on the extent of these losses under normal conditions. Then we need to know how the quantities lost vary with dietary factors such as diet intake, fibre level, protein level, and amino acid adequacy. Finally, we need infcrmation on how these losses vary with genetic strain, health, and other factors.

\section{Metabolic effects on reproduction}

As described previously, we need to know which components of the metabolic state are most closely associated with reproductive performance, quantitative estimates of these relationships, and further understanding of the timing of critical periods when metabolic state influences the developing ovarian follicle (Foxcroft et al. 1995) or other components of reproduction.

\section{SUMMARY}

The present paper describes both nutrient-partitioning and metabolic models as applied to pigs. It is suggested that nutrient-partitioning models are most useful for use as management aids for commercial pork production, but that metabolic models may be more useful in understanding biological mechanisms. There is a pressing need for more quantitative information on potential protein deposition rates, the relationship between protein deposition and energy intake, endogenous amino acid losses, and metabolic effects on reproduction, all under varying conditions of genetic strain, health, ambient temperature, stocking density, and other factors. 


\section{REFERENCES}

Baldwin, R. L., France, J. \& Gill, M. (1987). Metabolism of the lactating cow. I. Animal elements of a mechanistic model. Journal of Dairy Research 54, 77-105.

Bastianelli, D., Sauvant, D. \& Rérat, A. (1996). Mathematical modeling of digestion and nutrient absorption in pigs. Journal of Animal Science 74, 1873-1887.

Batterham, E. S., Andersen, L. M., Baigent, D. R. \& White, E. (1990). Utilization of ideal digestible amino acids by growing pigs: effect of dietary lysine concentration on efficiency of lysine retention. British Journal of Nutrition 64, 81-94.

Bikker, P. (1994). Protein and lipid accretion in body components of growing pigs. Effects of body weight and nutrient intake. PhD Thesis, Agricultural University of Wageningen, The Netherlands.

Bikker, P., Verstegen, M. W. A. \& Campbell, R. G. (1996). Performance and body composition of finishing gilts ( 45 to 85 kilograms) as affected by energy intake and nutrition in earlier life: I. Protein and lipid accretion in body components. Journal of Animal Science 74, 817-826.

Black, J. L. (1995). The testing and evaluation of models. In Modelling Growth in the Pig. European Association for Animal Production Publication no. 78, pp. 23-31 [P. J. Moughan, M. W. A. Verstegen and M. I. VisserReyneveld, editors]. Wageningen: Wageningen Pers.

Black, J. L., Campbell, R. G., Williams, I. H., James, K. J. \& Davies, G. T. (1986). Simulation of energy and amino acid utilisation in the pig. Research and Development in Agriculture 3, 121-145.

Booth, P. J. (1990). Metabolic influences on hypothalamic-pituitary-ovarian function in the pig. Journal of Reproduction and Fertility 40, Suppl., 89-100.

Campbell, R. G. \& Taverner, M. R. (1988). Genotype and sex effects on the relationship between intake and protein deposition in growing pigs. Journal of Animal Science 66, 676-686.

de Greef, K. H. (1992). Prediction of production. Nutrition induced tissue partitioning in growing pigs. PhD Thesis, Agricultural University of Wageningen, The Netherlands.

de Lange, C. F. M. \& Schreurs, H. W. E. (1995). Principles of model application. In Modelling Growth in the Pig. European Association for Animal Production Publication no. 78, pp. 187-208 [P. J. Moughan, M. W. A. Verstegen and M. I. Visser-Reyneveld, editors]. Wageningen: Wageningen Pers.

Foxcroft, G. R., Aherne, F. X., Clowes, E. C., Miller, H. \& Zak, L. (1995). Sow fertility: The role of suckling inhibition and metabolic status. In Animal Science Research and Development: Moving Toward a New Century, pp. 377-393 [M. Ivan, editor]. Ottawa: Centre for Food and Animal Research, Agriculture and AgriFood Canada.

Fuller, M. F., McWilliam, R., Wang, T. C. \& Giles, L. R. (1989). The optimum dietary amino acid pattern for growing pigs. 2. Requirements for maintenance and for tissue protein accretion. British Journal of Nutrition 62, 255-267.

Klasing, K. (1994). Interactions between nutrition and immunity. Proceedings, Allen D. Leman Swine Conference, pp. 35-39. St Paul, MN: University of Minnesota.

Koketsu, Y., Dial, G. D., Pettigrew, J. E., Marsh, W. E. \& King, V. L. (1996). Influence of imposed feed intake patterns during lactation on reproductive performance and on circulating levels of glucose, insulin, and luteinizing hormone in primiparous sows. Journal of Animal Science 74, 1036-1046.

Krick, B. J., Boyd, D. R., Roneker, K. R., Beermann, D. H., Bauman, D. E., Ross, D. A. \& Meisinger, D. J. (1993). Porcine somatotropin affects the dietary lysine requirement and net lysine utilization for growing pigs. Journal of Nutrition 123, 1913-1922.

Möhn, S., Fuller, M. F., Ball, R. \& de Lange, C. F. M. (1996). Measurement of lysine oxidation in growing pigs by continuous infusion of $\mathrm{L}-1\left[{ }^{14} \mathrm{C}\right]$-lysine: influence of feeding frequency. Journal of Animal Science 74, Suppl. 1, 175 Abstr.

Moughan, P. J. (1995). Modelling protein metabolism in the pig-critical evaluation of a simple reference model. In Modelling Growth in the Pig. European Association for Animal Production Publication no. 78, pp. 103-112 [P. J. Moughan, M. W. A. Verstegen and M. I. Visser-Reyneveld, editors]. Wageningen: Wageningen Pers.

Moughan, P. J., Verstegen, M. W. A. \& Visser-Reyneveld, M. I. (editors) (1995). Modelling Growth in the Pig. European Association for Animal Production Publication no. 78. Wageningen: Wageningen Pers.

Pettigrew, J. E., Gill, M., France, J. \& Close, W. H. (1992a). A mathematical integration of energy and amino acid metabolism of lactating sows. Journal of Animal Science 70, 3742-3761.

Pettigrew, J. E., Gill, M., France, J. \& Close, W. H. (1992b). Evaluation of a mathematical model of lactating sow metabolism. Joumal of Animal Science 70, 3762-3773.

Pettigrew, J. E., McNamara, J. P., Tokach, M. D., King, R. H. \& Crooker, B. A. (1993). Metabolic connections between nutrient intake and lactational performance in the sow. Livestock Production Science 35, 137-152.

Pettigrew, J. E. \& Tokach, M. D. (1993). Metabolic influences on sow reproduction. Pig News and Information $14,69 \mathrm{~N}-72 \mathrm{~N}$

Schinckel, A. P., Preckel, P. V. \& Einstein, M. E. (1996). Prediction of daily protein accretion rates of pigs from estimates of fat-free lean gain between 20 and 120 kilograms live weight. Journal of Animal Science 74, 498503. 
Standing Committee on Agriculture, Pig Subcommittee (1987). Feeding Standards for Australian Livestock. Pigs. Melbourne, Australia: CSIRO.

Walker, R. J. \& Wiseman, B. S. (1994). Growth performance of segregated early weaned (SEW) pigs compared to their conventionally weaned littermates. Journal of Animal Science 72, Suppl. 1, 377 Abstr.

Williams, N. H., Stahly, T. S. \& Zimmerman, D. R. (1994). Impact of immune system activation on growth and amino acid needs of pigs from 6 to $114 \mathrm{~kg}$ body weight. Journal of Animal Science 72, Suppl. 1, 57 Abstr. 